\title{
Structure, Dynamic Behavior, and Catalytic Activity of a Novel Ruthenium Cyclopentadienyl Complex with a Tridentate $\mathbf{P}, \mathbf{P}, \mathbf{O}$ Ligand
}

\author{
Robert C. van der Drift, Elisabeth Bouwman,* and Eite Drent \\ Leiden Institute of Chemistry, Gorlaeus Laboratories, Leiden University, P.O. Box 9502, \\ 2300 RA Leiden, The Netherlands \\ Huub Kooijman and Anthony L. Spek \\ Bijvoet Center for Biomolecular Research, Crystal and Structural Chemistry, Utrecht \\ University, Padualaan 8, $3584 \mathrm{CH}$ Utrecht, The Netherlands \\ A. Bart van Oort and Wilhelmus P. Mul \\ Shell International Chemicals BV, Shell Research and Technology Center Amsterdam, \\ Badhuisweg 3, 1031 CM Amsterdam, The Netherlands
}

Received March 21, 2002

\begin{abstract}
Reaction of 1,2-bis(bis(o-methoxyphenyl)phosphino)ethane (o-MeO-dppe) with [RuCICp$\left.\left(\mathrm{PPh}_{3}\right)_{2}\right](\mathbf{1})$ at $135^{\circ} \mathrm{C}$ results in the formation of $\left(\eta^{5}\right.$-cyclopentadienyl)[1-(bis(o-methoxyphe-

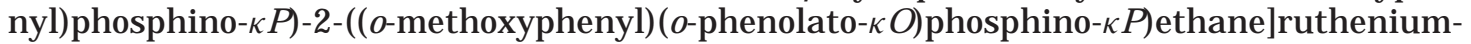
(II) ([RuCp(tappe)]; 3), which constitutes the first example of a ruthenium cycl opentadienyl complex with a tridentate $P, P, O$ ligand. The X-ray structure of $\mathbf{3}$ has been determined to elucidate its solid-state structure, which shows evidence for a $\mathrm{CH} / \pi$ interaction. An NMR study corroborates this finding, and temperature-dependent ${ }^{31} \mathrm{P}$ and ${ }^{1} \mathrm{H}$ NMR spectra reveal the dynamic behavior of $\mathbf{3}$ in solution. Complex $\mathbf{3}$ shows catalytic activity in the isomerization of allylic alcohols to carbonyl compounds.
\end{abstract}

\section{Introduction}

Butadiene with its two reactive double bonds forms an interesting starting compound in organic synthesis. ${ }^{1}$ A potentially new, useful application could be hydration of butadiene to give allylic alcohols (eq 1), which in turn can serve as intermediates in the synthesis of carbonyl compounds as shown in eq $2 .^{2}$ Most favorably for an

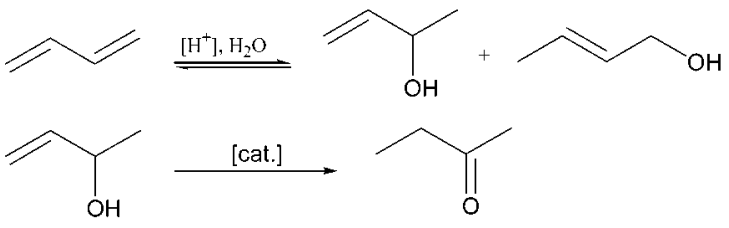

industrial application would be to perform both reactions in one reactor, thereby using the thermodynamic gain in carbonyl formation to drive the reaction to completion. Unfortunately, butadiene is a very efficient poison for catalysis of the isomerization reaction, and so far, only one system has been found capable of catalyzing the one-pot reaction of butadiene to butanone (methyl ethyl ketone, MEK). ${ }^{3-5}$

(1) March, J . Advanced Organic Chemistry; Wiley-Interscience: New York, 1985.

(2) Van der Drift, R. C.; Bouwman, E.; Drent, E. J . Organomet. Chem. 2002, 650, 1.

(3) Stunnenberg, F.; Niele, F. G. M.; Drent, E. Inorg. Chim. Acta 1994, 222, 225.

(4) Drent, E., Eur. Pat. 457,387, 1991.
In the course of our studies to find other, more active catalysts for the one-pot synthesis of MEK, an interesting class of RuCp complexes with didentate phosphine ligands has been synthesized. ${ }^{6}$ This class of catalysts appeared highly active in the isomerization of allylic alcohols. Although not able to isomerize 3-buten-2-ol to MEK in the presence of butadiene, these complexes instead show a surprising activity in ether formation. Thus, in the presence of a conjugated diene, [RuClCp$(\mathrm{P}-\mathrm{P})]\left(\mathrm{P}-\mathrm{P}=\mathrm{Ph}_{2} \mathrm{P}\left(\mathrm{CH}_{2}\right)_{n} \mathrm{PPh}_{2} ; \mathrm{n}=1-3\right)$ catalyzes the conversion of allyl alcohol to diallyl ether. The complex [RuClCp(o-MeO-dppe)] (2, o-MeO-dppe = 1,2-bis(bis(omethoxyphenyl)phosphino)ethane), however, catalyzes this ether-forming reaction also in the absence of a diene. ${ }^{6}$ In this way, allyl aryl ethers and allyl alkyl ethers can be prepared directly from allyl alcohol. The rates are high, and turnover numbers (TONs) up to 3000 were achieved, exceeding by far the activity of known palladium catalysts. ${ }^{7-12}$

(5) Van der Drift, R. C.; Mul, W. P.; Bouwman, E.; Drent, E. Chem Commun. 2001, 2746.

(6) Van der Drift, R. C.; Vailati, M.; Bouwman, E.; Drent, E. J . Mol . Catal. A: Chem. 2000, 159, 163

(7) Sakamoto, M.; Shimizu, I.; Yamamoto, A. Bull. Chem. Soc. J pn. 1996, 69, 1065.

(8) Satoh, T.; Ikeda, M.; Miura, M.; Nomura, M. J . Org. Chem. 1997, 62, 4877.

(9) Bergbreiter, D. E.; Weatherford, D. A. J . Chem. Soc., Chem. Commun. 1989, 883.

(10) Yamamoto, T.; Akimoto, M.; Saito, O.; Yamamoto, A. Organometallics 1986, 5, 1559.

(11) Yang, S.-C.; Hung, C.-W. J . Org. Chem. 1999, 64, 5000. 
These results prompted us to study the o-M eO-dppe ligand further. It is known ${ }^{13}$ that at higher temperatures this type of ligand can lose a methyl group to give a (coordinating) phenolate anion. Some ruthenium complexes have been reported in which abstraction of $\mathrm{MeCl}$ from a complex with a monodentate, methoxysubstituted arylphosphine ligand results in a chelating $\mathrm{P}, \mathrm{O}$ ligand ${ }^{14-16}$ or even a tridentate $\mathrm{O}, \mathrm{P}, \mathrm{O}$ ligand..$^{13}$ Only one of the published complexes contains a (substituted) $\mathrm{Cp}$ group. ${ }^{14}$ Sometimes, $\mathrm{MeO}$ groups can function as labile ligands in competition with the phosphine donor atom, and this then gives rise to a dynamic behavior in solution that can be monitored by temperature-dependent NMR. ${ }^{17,18}$

Herein we wish to report the synthesis, structure, and catalytic properties of a novel complex, ( $\eta^{5}$-cyclopentadienyl)[1-(bis(o-methoxyphenyl)phosphino- $\kappa$ P)-2-((o-methoxyphenyl)(o-phenolate $\kappa \mathrm{O}$ ) phosphino- $\kappa \mathrm{P}$ )ethane]ruthe nium(II) ([RuCp(tappe)]; 3), which results from $\mathrm{MeCl}$ abstraction from $\mathbf{2}$ at $135{ }^{\circ} \mathrm{C}$.

\section{Experimental Section}

General Comments. The ligand o-MeO-dppe has been prepared previously in our laboratory. ${ }^{19}\left[\mathrm{RuCl} \mathrm{Cp}\left(\mathrm{PPh}_{3}\right)_{2}\right](\mathbf{1})^{20}$ and [RuClCp(o-MeO-dppe)] (2) ${ }^{6}$ were prepared according to literature procedures. Other reagents and solvents were commercially available and used without further purification. All catalytic reactions were performed under an argon atmosphere using standard Schlenk techniques. Quantitative gas liquid chromatography analyses were carried out on a Chrompack apparatus equipped with a CP wax 58 (FFAP) CB column $(25 \mathrm{~m} \times 1.2 \mu \mathrm{m})$ with toluene as internal standard. Melting points were measured on a Büchi apparatus and are uncorrected. Mass spectra were recorded on a Finnigan MAT 900 equipped with a custom-made el ectrospray interface (ESI). Elemental analyses were performed on a Perkin-EImer Series II 2400 CHNS/O Analyzer.

NMR Experiments. ${ }^{1} \mathrm{H}$ NMR spectra $(400 \mathrm{MHz}),{ }^{13} \mathrm{C}\left\{{ }^{1} \mathrm{H}\right\}$ NMR spectra (100.6 M Hz), and ${ }^{31} \mathrm{P}\left\{{ }^{1} \mathrm{H}\right\}$ NMR spectra (161.9 $\mathrm{MHz}$ ) were measured on a Varian I nova-400. ${ }^{1} \mathrm{H}$ NMR spectra (300 M Hz) spectra for $\mathbf{2}$ and ${ }^{1} \mathrm{H}-{ }^{31} \mathrm{P}$ COSY spectra for $\mathbf{3}$ were recorded on a Bruker DPX-300. Chemical shifts are reported in ppm. Proton chemical shifts are relative to TMS, carbon chemical shifts are referenced to internal solvent carbon atoms, and phosphorus chemical shifts are relative to $85 \%$ aqueous $\mathrm{H}_{3} \mathrm{PO}_{4}$. The spectra were taken in the temperature range from room temperature to $-100^{\circ} \mathrm{C}$. The COSY, PFG HSQC, PFG HMQC, and ${ }^{1} \mathrm{H}-{ }^{31} \mathrm{P}$ COSY spectra were obtained using standard Varian or Bruker pulse sequences. The NOESY experiments were performed with a mixing time of $1.5 \mathrm{~s}$ and 16 scans for each t increment, and a delay of $5 \mathrm{~s}$ was incorporated prior to each scan.

(12) Bricout, H.; Carpentier, J .-F.; Mortreux, A. J . Mol. Catal. A: Chem. 1998, 136, 243.

(13) Yamamoto, Y.; Sato, R.; Matsuo, F.; Sudoh, C.; I goshi, T. Inorg. Chem. 1996, 35, 2329.

(14) Canestrari, M.; Chaudret, B.; Dahan, F.; Huang, Y.-S.; Poilblanc, R.; Kim, T.-C.; Sanchez, M. J . Chem. Soc., Dalton Trans. 1990 1179.

(15) Yamamoto, Y.; Sato, R.; Ohshima, M.; Matsuo, F.; Sudoh, C. J . Organomet. Chem. 1995, 489, C68.

(16) Yamamoto, Y.; Sugawara, K.; Aiko, T.; Ma, J .-F.J . Chem. Soc. Dalton Trans. 1999, 4003.

(17) Bader, A.; Lindner, E. Coord. Chem. Rev. 1991, 108, 27.

(18) Lindner, E.; Pautz, S.; Haustein, M. Coord. Chem. Rev. 1996 155, 145.

(19) Angulo, I. M.; Bouwman, E.; Lutz, M.; Mul, W. P.; Spek, A. L. Inorg. Chem. 2001, 40, 2073.

(20) Bruce, M. I.; Hameister, C.; Swincer, A. G.; Wallis, R. C. Inorg. Synth. 1982, 21, 78.

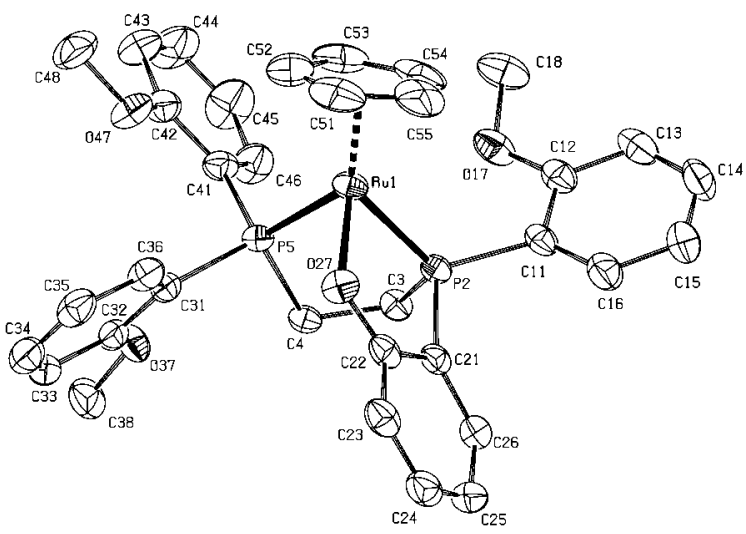

Figure 1. ORTEP drawing of $\mathbf{3}$ with the adopted atom labeling. Displacement ellipsoids are drawn at the $50 \%$ probability level. Hydrogen atoms are omitted for clarity. The (disordered) solvent molecule is not shown.

Synthesis of [RuCICp(o-MeO-dppe)] (2). The synthesis of $\mathbf{2}$ has been reported previously, but without ${ }^{1} \mathrm{H}$ NMR data. ${ }^{6}$ Lower reaction temperatures $\left(T<100^{\circ} \mathrm{C}\right)$ result in longer reaction times, but $\mathbf{2}$ can then be obtained without contamination of 3. Anal. Calcd for $\mathrm{C}_{35} \mathrm{H}_{37} \mathrm{ClO}_{4} \mathrm{P}_{2} \mathrm{Ru} \cdot 1.5$ (toluene): C, 57.50; $\mathrm{H}, 5.16$. Found: $\mathrm{C}, 57.77 ; \mathrm{H}, 5.10{ }^{1}{ }^{1} \mathrm{H} \mathrm{NMR}\left(\mathrm{CDCl}_{3}\right.$, room temperature): $8.16(\mathrm{br} \mathrm{s}, 2 \mathrm{H}, \mathrm{Ar} \mathrm{O}-\mathrm{H}), 7.25\left(\mathrm{dt}, 2 \mathrm{H}, \mathrm{Ar} \mathrm{H},{ }^{3} \mathrm{Hн}\right.$ $\left.=15 \mathrm{~Hz},{ }^{3} \mathrm{H} \mathrm{H}^{2} 1.5 \mathrm{~Hz}\right), 7.25\left(\mathrm{t}, 2 \mathrm{H}, \mathrm{ArH},{ }^{3} \mathrm{Hн}=7 \mathrm{~Hz}\right), 7.02$ $(\mathrm{t}, 2 \mathrm{H}, \mathrm{Ar} \mathrm{H}, 3 \mathrm{JH}=7 \mathrm{~Hz}), 6.87(\mathrm{br} \mathrm{s}, 2 \mathrm{H}, \mathrm{o}-\mathrm{Ar} \mathrm{H}), 6.72(\mathrm{t}, 4 \mathrm{H}$, $\left.\mathrm{Ar} \mathrm{H}, 3 \mathrm{~J} \mathrm{HH}^{2} 7 \mathrm{~Hz}\right), 4.52(\mathrm{~s}, 5 \mathrm{H}, \mathrm{Cp}), 3.41(\mathrm{~s}, 6 \mathrm{H}, \mathrm{OMe}), 3.25$ (s, 6H, OMe), 2.5-2.8 (br m, 4H, $\mathrm{CH}_{2}$ ).

Synthesis of [RuCp(tappe)] (3). A solution of $\mathbf{1}$ (1.01 g $1.39 \mathrm{mmol}$ ) and o-MeO-dppe $(0.718 \mathrm{~g}, 1.39 \mathrm{mmol})$ in p-xylene $(50 \mathrm{~mL})$ was refluxed for $8 \mathrm{~h}$. The resulting clear orange solution was reduced in volume to approximately $1 \mathrm{~mL}$ on a rotary evaporator. The orange-yell ow product was preci pitated with hexane. It was subsequently purified by recrystallization from hot acetone, yielding orange crystals $(0.41 \mathrm{~g}, 44 \%)$. MS $(E S I): m / z 670\left([M+H]^{+}\right)$. Mp: $182{ }^{\circ} \mathrm{C}$. Anal. Calcd for $\mathrm{C}_{34} \mathrm{H}_{34} \mathrm{O}_{4} \mathrm{P}_{2} \mathrm{Ru} \cdot$ (acetone): $\mathrm{C}, 61.07 ; \mathrm{H}, 5.50$. Found: C, 61.02; $\mathrm{H}$, 5.34. ${ }^{\mathrm{H}}\left\{{ }^{31} \mathrm{P}\right\} \mathrm{NMR}\left(\mathrm{CD}_{2} \mathrm{Cl}_{2}\right.$, room temperature; see Figure 1 for atom numbering): 8.5 (d, $\left.1 \mathrm{H},{ }^{3} \mathrm{\jmath нн}=6.8 \mathrm{~Hz}, \mathrm{H} 36\right), 7.5$ (d, $\left.1 \mathrm{H},{ }^{3} \mathrm{Hн}=7.6 \mathrm{~Hz}, \mathrm{H} 16\right), 7.4\left(\mathrm{t}, 1 \mathrm{H}, 3_{\mathrm{H}} \mathrm{Hн}=7.6 \mathrm{~Hz}, \mathrm{H} 14\right)$, $7.3\left(\mathrm{t}, 1 \mathrm{H}, 3 \mathrm{~J}_{\mathrm{нн}}=7.6 \mathrm{~Hz}, \mathrm{H} 34\right), 7.2(\mathrm{t}, 1 \mathrm{H}, 3 \mathrm{\jmath}$ нн $=7.6 \mathrm{~Hz}, \mathrm{H} 44)$, $7.2\left(\mathrm{~d}, 1 \mathrm{H},{ }^{3} \mathrm{\jmath нн}=6.8 \mathrm{~Hz}, \mathrm{H} 26\right), 7.1\left(\mathrm{t}, 1 \mathrm{H},{ }^{3} \mathrm{\jmath нн}=7.6 \mathrm{~Hz}\right.$, H35), $7.0(\mathrm{~m}, 3 \mathrm{H}, \mathrm{H} 13, \mathrm{H} 15, \mathrm{H} 46), 6.88(\mathrm{~d}, 1 \mathrm{H}, 3 \mathrm{3} \mathrm{HH}=6.8 \mathrm{~Hz}$, $\mathrm{H} 43), 6.86\left(\mathrm{t}, 1 \mathrm{H}, 3 \mathrm{JH}_{\mathrm{HH}}=7.6 \mathrm{~Hz}, \mathrm{H} 45\right), 6.8(\mathrm{t}, 1 \mathrm{H}, 3 \mathrm{HH}=6.8$ $\mathrm{Hz}, \mathrm{H} 24), 6.7\left(\mathrm{~d}, 1 \mathrm{H},{ }^{3} \mathrm{\mu н}=7.6 \mathrm{~Hz}, \mathrm{H} 33\right), 6.4\left(\mathrm{~d}, 1 \mathrm{H},{ }^{3} \mathrm{~J} \mathrm{H}^{2}\right.$ $6.8 \mathrm{~Hz}, \mathrm{H} 23), 6.3\left(\mathrm{t}, 1 \mathrm{H},{ }^{3}\right.$ нн $\left.=6.8 \mathrm{~Hz}, \mathrm{H} 25\right), 4.08(\mathrm{~s}, 5 \mathrm{H}, \mathrm{Cp})$, $3.8(\mathrm{~s}, 3 \mathrm{H}, \mathrm{MeO}$, ring $\mathrm{A}), 3.7(\mathrm{~s}, 3 \mathrm{H}, \mathrm{MeO}$, ring $\mathrm{D}), 3.4(\mathrm{~s}, 3 \mathrm{H}$,

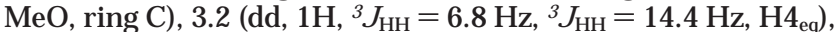
$\left.3.1\left(\mathrm{td}, 1 \mathrm{H}, 3 \mathrm{JH}_{\mathrm{HH}}=6.8 \mathrm{~Hz},{ }^{3}\right)_{\mathrm{HH}}=13.6 \mathrm{~Hz}, \mathrm{H}_{\mathrm{ax}}\right), 2.6(\mathrm{dd}, 1 \mathrm{H}$, 3) $\mathrm{HH}^{2}=6.8 \mathrm{~Hz}$, 3 $\left.\mathrm{JHH}_{\mathrm{HH}}=14.4 \mathrm{~Hz}, \mathrm{H}_{\mathrm{eq}}\right), 1.1\left(\mathrm{td}, 1 \mathrm{H}, 3_{\mathrm{HH}}=6.8\right.$ $\left.\mathrm{Hz},{ }^{3}{ }_{\text {нн }}=13.6 \mathrm{~Hz}, \mathrm{H} 44_{\mathrm{ax}}\right) .{ }^{13} \mathrm{C} \mathrm{NMR}\left(\mathrm{CD}_{2} \mathrm{Cl}_{2}\right.$, room temperature; see Figure 1 for atom numbering): 178 (C22), 161.1 (C12), 160.3 (C32), 159.2 (C42), 140.3 (C36), 133.2 (C16), 131.7 (C34), 131.5 (C14), 131 (C41), 130.9 (C26), 130.4 (C46), 130.3 (C24), 130.0 (C44), 126.5 (C11), 121.1 (C15), 120.7 (C45), 120.5 (C35), 120 (C31), 119.0 (C23), 113.1 (C25), 111.4 (C13), 111.4 (C43), 111.0 (C33), $78.7(\mathrm{Cp}), 55.3$ ( $\mathrm{MeO}$, ring A), $55.2(\mathrm{MeO}$, ring D), 55.1 ( $\mathrm{MeO}$, ring $\mathrm{C}$ ), 30.8 (C3), 26.9 (C4). The signal for $\mathrm{C} 21$ could not be located. ${ }^{31} \mathrm{P}\left\{{ }^{1} \mathrm{H}\right\}$ NMR $\left(\mathrm{CD}_{2} \mathrm{Cl}\right.$, room temperature; see Figure 1 for atom numbering): 89.2 (broad $\mathrm{s}, \mathrm{P} 3$ ), 80.1 (broad s, P4). ${ }^{11} \mathrm{P}\left\{{ }^{1} \mathrm{H}\right\} \mathrm{NMR}\left(\mathrm{CD}_{2} \mathrm{Cl}_{2},-100^{\circ} \mathrm{C}\right) 87.6\left(\mathrm{~d},{ }^{2} \mathrm{pP}=\right.$ $32 \mathrm{~Hz}), 87.3\left(\mathrm{~d},{ }^{2} \mathrm{~J} p \mathrm{pP}=32 \mathrm{~Hz}\right), 86.8\left(\mathrm{~d},{ }^{2} \mathrm{Jpp}=32 \mathrm{~Hz}\right), 73.9(\mathrm{~d}$, ${ }^{2} \mathrm{f} P \mathrm{PP}=32 \mathrm{~Hz}$ ).

Crystallographic Analysis. Crystals of $\mathbf{3}$ were grown by vapor diffusion of $n$-hexane into a toluene solution of the complex at room temperature. A yellow, block-shaped crystal was glued to the tip of a glass fiber and transferred into the cold nitrogen stream on a Nonius KappaCCD diffractometer 
Table 1. Crystal Data and Structure Refinement for 3

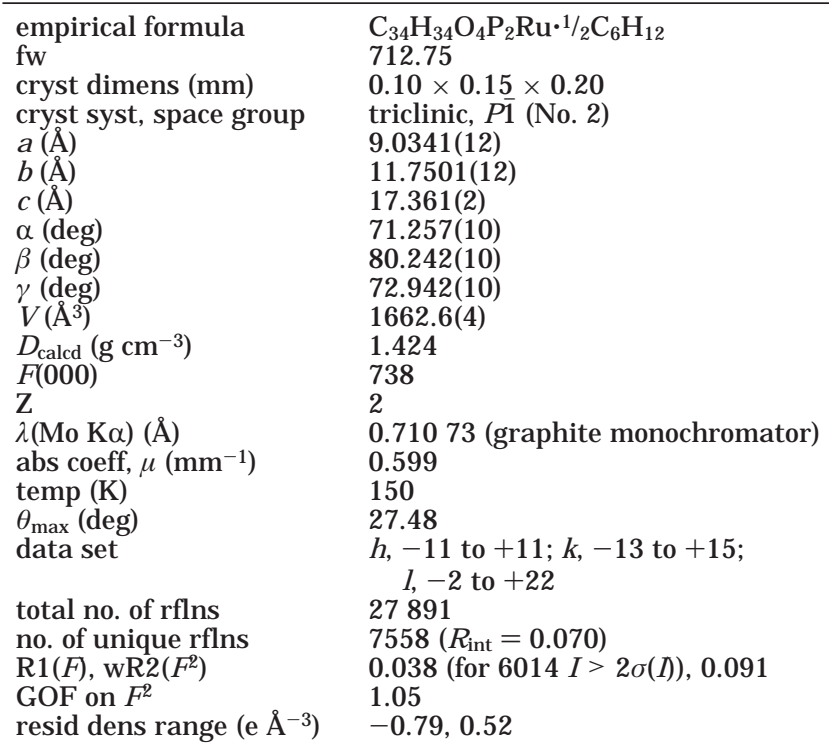

on a rotating anode. Crystal data and details on data collection and refinement are given in Table 1 . Reduced-cell calculations did not indicate higher lattice symmetry. ${ }^{21}$ Data were corrected for $L p$ effects but not for absorption. The structure was solved by automated direct methods and subsequent difference $\mathrm{F}$ ourier techniques. ${ }^{22}$ Refinement on $\mathrm{F}^{2}$ was carried out by fullmatrix least-squares techniques; ${ }^{23}$ no observance criterion was applied during refinement. Hydrogen atoms were included in the refinement on calculated positions riding on their carrier atoms. A void with a total volume of $220 \AA^{3}$ per unit cell, located on a crystallographic inversion center, was found to be filled with disordered hexane. No satisfactory model could be refined. The disordered electron density was taken into account with the SQUEEZE procedure, as implemented in PLATON.${ }^{24} A$ total electron count of 43 per unit cell was found and corrected for. All non-hydrogen atoms were refined with anisotropic displacement parameters. The hydrogen atoms were refined with a fixed isotropic displacement parameter related to the value of the equivalent isotropic displacement parameter of their carrier atom. Neutral atom scattering factors and anomalous dispersi on corrections were taken from ref $25^{25}$. Geometrical calculations and illustrations were performed with PLATON. ${ }^{24}$

Catalytic Experiments. In a typical experiment, 3-buten2-ol $(1.72 \mathrm{~g}, 23.9 \mathrm{mmol})$ was brought into a two-neck roundbottom flask equipped with a reflux condenser and a septum together with $3(5.82 \mathrm{mg}, 8.70 \mu \mathrm{mol})$ and toluene $(0.40 \mathrm{~g}, 4.40$ $\mathrm{mmol}$ ) as internal standard. The flask was lowered into a preheated oil bath at $100{ }^{\circ} \mathrm{C}$. After the appropriate reaction time, a sample was taken through the septum with an airtight syringe and subsequently analyzed with GLC. In some experiments isoprene ( $2 \mathrm{~mL}, 20 \mathrm{mmol}$ ) was injected prior to addition of substrate.

\section{Results and Discussion}

Complex Synthesis. Reaction of 1 with o-MeO-dppe may yield two products, depending on the reaction

(21) Spek, A. L. J . Appl. Crystallogr. 1988, 21, 578

(22) Sheldrick, G. M. SHELXS86: Program for Crystal Structure Determination; University of Göttingen, Göttingen, Germany, 1986.

(23) Sheldrick, G. M. SHELXL-97: Program for Crystal Structure Refinement; University of Göttingen, Göttingen, Germany, 1997.

(24) Spek, A. L. PLATON: A Multi-Purpose Crystallographic Tool, Utrecht University, The Netherlands, 2000. Internet: http//www.cryst.chem.uu.nl/platon.

(25) International Tables for Crystallography; Wilson, A. J . C., Ed. Kluwer Academic: Dordrecht, The Netherlands, 1992; Vol. C.
Scheme $1^{a}$

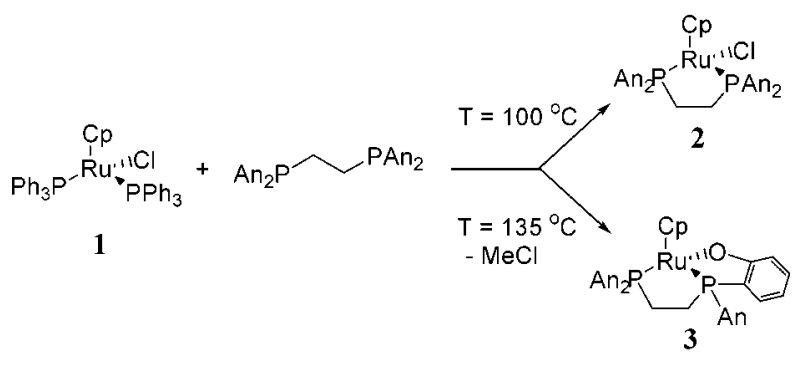

a $\mathrm{An}=\mathrm{o}-\mathrm{MeO}-\mathrm{Ph}$.

Table 2. Selected Bond Distances ( $\AA$ ), Angles (deg), and Torsion Angles (deg) for 3

\begin{tabular}{llll}
\hline \multicolumn{4}{c}{ Bond Distances } \\
Ru1-P2 & $2.2396(7)$ & P2-C3 & $1.838(3)$ \\
Ru1-P5 & $2.2844(8)$ & P5-C4 & $1.846(3)$ \\
Ru1-Cp & $1.8497(15)$ & C3-C4 & $1.526(3)$ \\
Ru1-O27 & $2.1153(17)$ & P2-C21 & $1.804(2)$ \\
P2-C11 & $1.826(2)$ & P5-C41 & $1.832(2)$ \\
P5-C31 & $1.836(2)$ & &
\end{tabular}

\begin{tabular}{lrlr}
\multicolumn{5}{c}{ Bond Angles } \\
P2-Ru1-P5 & $82.99(3)$ & O27-Ru1-P2 & $82.38(5)$ \\
O27-Ru1-P5 & $92.91(5)$ & Cp-Ru1-P2 & $131.57(5)$ \\
Cp-Ru1-P5 & $128.25(5)$ & Cp-Ru1-O27 & $124.14(7)$ \\
Ru1-P2-C21 & $103.13(9)$ & Ru1-P2-C11 & $120.95(9)$ \\
Ru1-P5-C41 & $114.59(9)$ & Ru1-P5-C31 & $119.37(9)$ \\
Ru1-P2-C3 & $113.22(8)$ & Ru1-P5-C4 & $110.28(8)$ \\
C3-C4-P5 & $112.09(19)$ & P2-C3-C4 & $106.43(18)$ \\
C22-O27-Ru1 & $119.20(15)$ & & \\
\multicolumn{5}{c}{ Torsion Angles (deg) } \\
Ru1-P5-C31-C32 & $-167.20(17)$ \\
Ru1-P5-C41-C42 & & $-76.5(2)$ \\
Ru1-P2-C11-C12 & $-68.7(2)$ \\
Ru1-P2-C21-C22 & & $-0.6(2)$ \\
P2-C3-C4-P5 & $40.94(19)$
\end{tabular}

temperature. At temperatures below $100{ }^{\circ} \mathrm{C} \mathbf{2}$ is formed, with the o-MeO-dppe ligand still intact (Scheme 1). At higher temperatures $\left(\mathrm{T}>135^{\circ} \mathrm{C}\right) \mathrm{MeCl}$ is spontaneously abstracted from $\mathbf{2}$ to give $\mathbf{3}$. To the best of our knowledge, $\mathbf{3}$ is the first ruthenium complex with a tridentate $\mathrm{P}, \mathrm{P}, \mathrm{O}$ ligand, resulting from $\mathrm{MeCl}$ abstraction from a didentate phosphine ligand. The formation of $\mathbf{3}$ can be monitored conveniently by ${ }^{31 P}$ NMR. Disappearance of the singlet at 70.3 ppm and concomitant appearance of two broad singlets at 89.2 and 80.1 ppm are indicative of the formation of $\mathbf{3}$ at the expense of $\mathbf{2}$. The initial precipitated product usually contains some triphenylphosphine, but facile recrystallization from hot acetone results in the analytically pure complex.

X-ray Structure Determination. The molecular structure of $\mathbf{3}$ is shown in Figure 1 . Some selected bond distances and angles are listed in Table 2. If the $C p$ ligand is treated as a fac-coordinating tridentate ligand, the ruthenium possesses approximately an octahedral coordination geometry. Alternatively, the ruthenium can be regarded to bein a distorted-tetrahedral environment with $\mathrm{Cp}$ as a monodentate anion. The bonding of ruthenium to the two phosphorus atoms is asymmetrical, with Ru1-P2 being the shorter bond of the two. The Ru1-027 bond length of 2.1153(17) $\AA$ is between those reported for ruthenium $\eta^{6}$-aryl containing compounds $13,15,16$ and that reported for a ruthenium $\eta^{5}$ pentamethylcyclopentadienyl complex, ${ }^{14}$ as could be expected on electronic grounds. One of the methoxy oxygens (O37) is a considerable 5.2891(19) $\AA$ away from the ruthenium center. The two other methoxy oxygen 


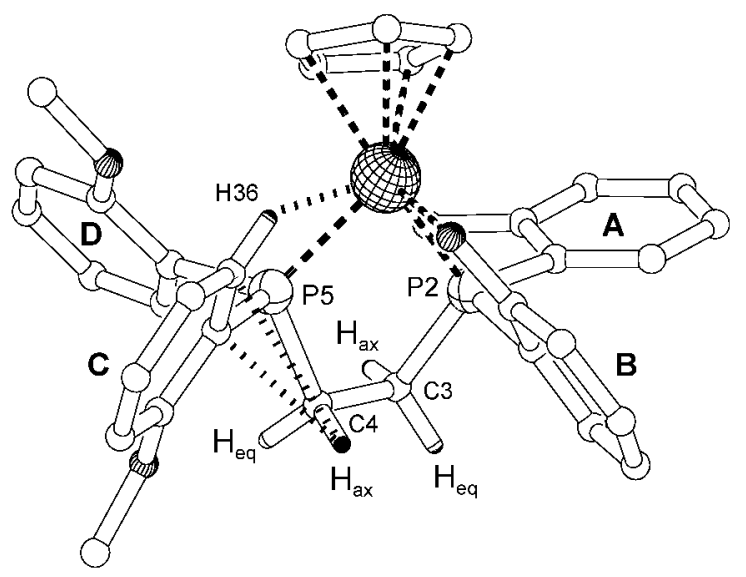

Figure 2. Molecular drawing of 3 with the adopted ring labeling. Indicated are $\mathrm{H} 36$ and the bridge protons of $\mathrm{C} 3$ and $\mathrm{C} 4\left(\mathrm{H}_{\mathrm{ax}}\right.$ and $\left.\mathrm{H}_{\mathrm{eq}}\right)$ and their interactions with the ruthenium center and ring $C$, respectively.

atoms, $\mathrm{O} 17$ and 047 , are relatively close to Ru1 at distances of 3.8598(19) and 3.966(2) $\AA$, respectively. However, those distances are too long to consider el ectrostatic interactions.

Two interesting interactions can be observed in the structure (Figure 2). The distance between Rul and the ortho hydrogen $\mathrm{H} 36$ is $3.14 \AA$, which is smaller than the sum of their contact radii $(3.50 \AA) .{ }^{26}$ Second, the ethylene bridge hydrogen $\mathrm{H} 4$ ax is close to the $\pi$-cloud of the nearby aromatic ring ( $\mathrm{CH} / \pi$ interaction), as evidenced by its short distances to C31 (2.84 $\AA$ ) and C32 $(3.12 \AA) .27$ These contacts also exist in solution, and a more elaborate discussion of both interactions will be given in the section on the solution structure of $\mathbf{3}$ (vide infra).

The two bite angles of the $\mathrm{P}, \mathrm{P}$ and $\mathrm{P}, \mathrm{O}$ didentate parts are essentially the same: $82.99(3)$ and $82.38(5)^{\circ}$, respectively. The P,P bite angle is only slightly smaller than the $83.5^{\circ}$ in $[R u C l C p(d p p e)]$ (dppe $=1,2$-bis(diphenylphosphino)ethane), ${ }^{28}$ while the O27-Ru1-P2 angle falls nicely in the range of reported values for other $\mathrm{P}, \mathrm{O}$ didentate ligands. ${ }^{14-16}$ The ruthenium center is part of two five-membered rings. The five-membered ring containing Ru1, 027 , and $\mathrm{P} 2$ is planar. The other five-membered ring includes both phosphorus atoms and the $\mathrm{C}_{2}$ bridge. This ring is in a conformation that can be best described as a slightly distorted envel ope, with C3 displaced by $0.574(2) \AA$ from the plane through the other four ring atoms. The groups attached to this ring are staggered with respect to each other.

Abstraction of a methyl group from one of the methoxy groups turns both Ru1 and P2 into chiral centers. In the molecular structure shown in Figure 1, P2 has an $\mathrm{S}$ configuration. Considering $\mathrm{Cp}$ as a monodentate ligand of high priority, Rul is similarly in a T-4-S configuration with priorities assigned as $\mathrm{Cp}>\mathrm{P} 2>\mathrm{P} 5$ $>027 .{ }^{29}$ Since the chiralities of the phosphorus and the ruthenium centers are coupled, only two of the four possible diastereomers can be formed: the aforemen-

(26) Bondi, A. J . Phys. Chem. 1964, 68, 441.

(27) Nishio, M.; Hirota, M.; Umezawa, $\mathrm{Y}$. The $\mathrm{CH} / \mathrm{Pi}$ Interaction: Evidence, Nature and Consequences; Wiley-VCH: New York, 1998.

(28) Suravajjala, S.; Porter, L. G. Acta Crystallogr., Sect. C 1993, 49, 1456.

(29) Stanley, K.; Baird, M. C. J . Am. Chem. Soc. 1975, 97, 6598. (h)

(g)

(f)

(e)

(d)

(c)

(b)
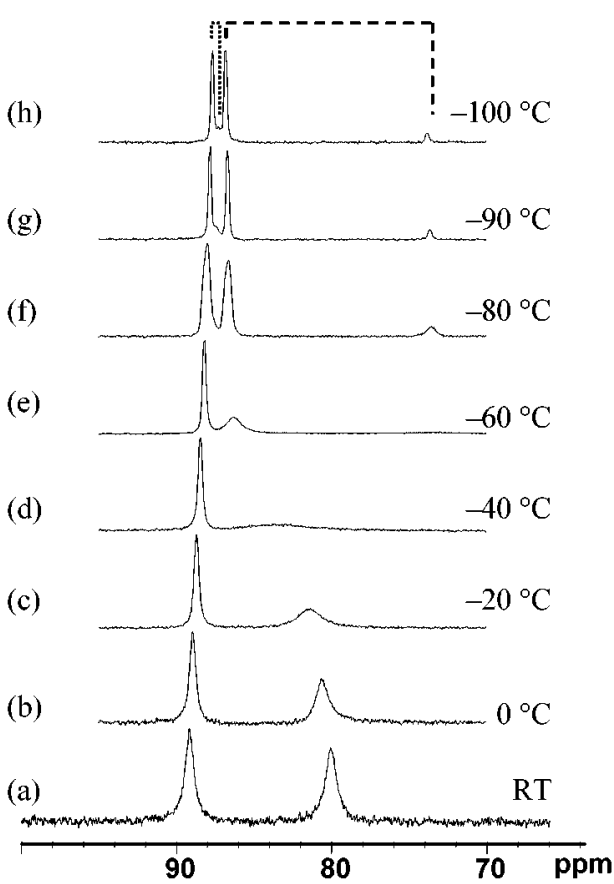

Figure 3. $161.9 \mathrm{MHz}{ }^{31} \mathrm{P} N M R$ spectra of 3 in $\mathrm{CD}_{2} \mathrm{Cl}_{2}$ as a function of temperature. Dashed lines indicate the two sets of signals corresponding to the same phosphorus atom in two different rotamers at $-100^{\circ} \mathrm{C}$.

tioned combination $\mathrm{P}_{S} R u_{S}$ and its counterpart $P_{R} R u_{R}$, which are related in the crystal structure by an inversion center and are, as an enantiomeric pair, not discernible with NMR.

Room-Temperature Solution Structure of 3. In addition to the solid-state structure, $\mathrm{a}^{1} \mathrm{H}$ and ${ }^{31} \mathrm{P}$ NMR study has been undertaken to assess the behavior of $\mathbf{3}$ in solution. The room-temperature ${ }^{31} \mathrm{P}$ NMR spectrum consists of two broad singlets at 89.2 and $80.1 \mathrm{ppm}$ (Figure 3 a) indicative of phosphorus atoms bonded to ruthenium as part of a five-membered ring, 6,30,31 in accordance with the solid-state structure. The roomtemperature ${ }^{1} \mathrm{H}$ NMR spectrum can be divided roughly into three sections. From left to right these sections signify the aromatic protons, the methoxy protons, and the ethylene bridge protons (Figure 4a). At each end of the spectrum one signal clearly stands out: an aromatic proton at $8.5 \mathrm{ppm}$ and a bridge proton at $1.1 \mathrm{ppm}$. To determine their origin and the reasons for their anomalous chemical shifts, complete assignment of all protons has been established, which proved to be nontrivial.

Due to the asymmetry in $\mathbf{3}, 16$ resonances are discernible in the aromatic region. Four sets of four aromatic protons and the corresponding methoxy groups were assigned by successive application of ${ }^{1} \mathrm{H}-{ }^{1} \mathrm{H}$ COSY and long-range ${ }^{1} \mathrm{H}-{ }^{13} \mathrm{C}$ correlation experiments. ${ }^{32}$ The only set of protons without a methoxy group is readily recognized as ring $B$ (Figure 2 ). Two ortho protons, bel onging to two different aromatic rings, exhibit a NOE cross peak with a bridge proton ( $\mathrm{H}_{\mathrm{ax}}$; vide infra) and can therefore be only part of rings $A$ and $D$. This directly leads to the assignment of the low-field signal at 8.5

(30) Morandini, F.; Consiglio, G.; Straub, B.; Ciani, G.; Sironi, A. J . Chem. Soc., Dalton Trans. 1983, 2293.

(31) Ohkita, K.; Kurosawa, H.; Hirao, T.; I keda, I. J . Organomet. Chem. 1994, 470, 179.

(32) See Supplementary Information for selected NMR spectra. 


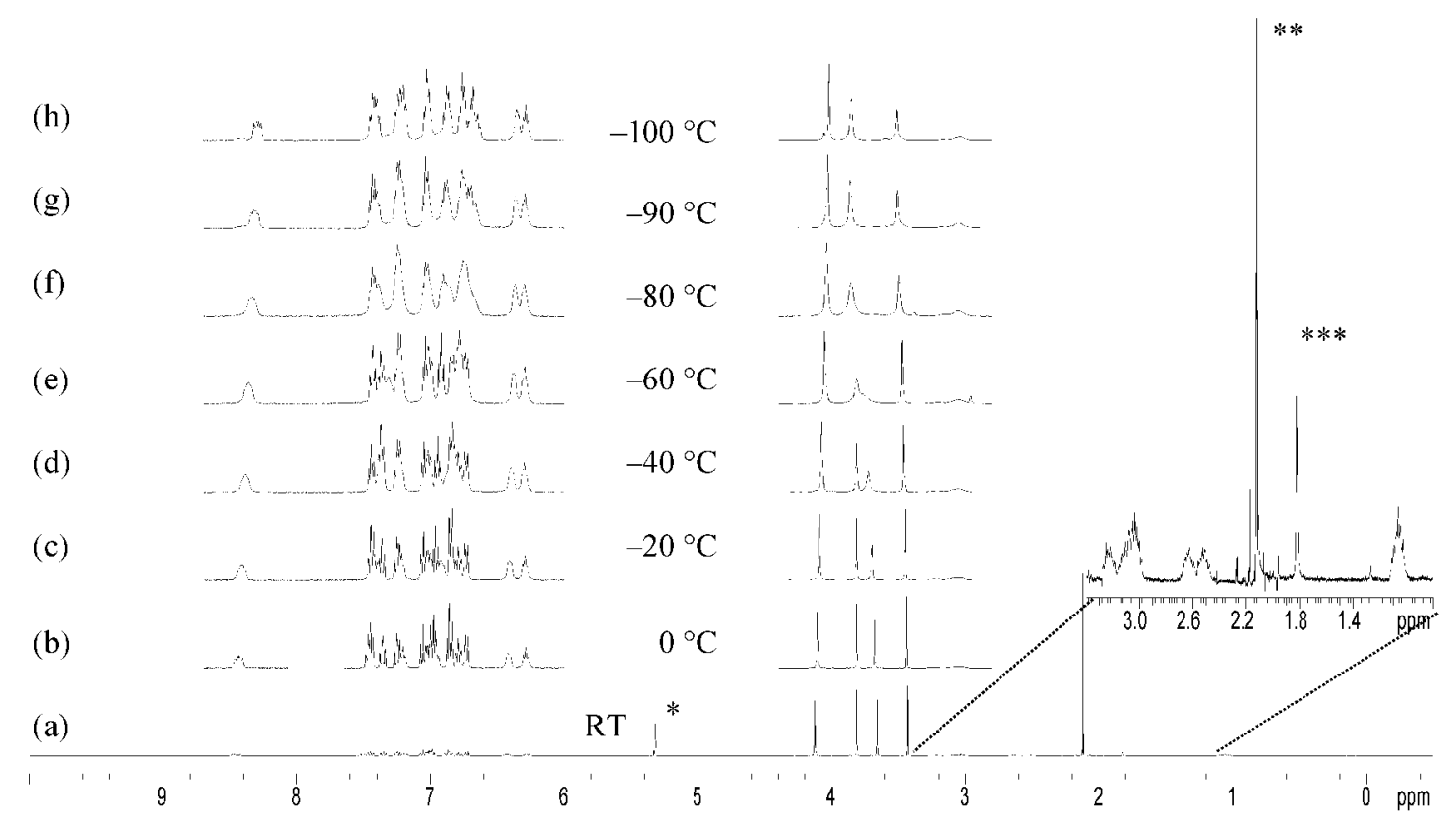

Figure 4. $400 \mathrm{MHz}{ }^{1} \mathrm{H}$ NMR spectra of 3 in $\mathrm{CD}_{2} \mathrm{Cl}_{2}$ as a function of temperature. The right-hand part corresponds to the $\mathrm{MeO}$ region, while the left-hand part shows the aromatic protons. In the room-temperature spectrum (a) all signals of $\mathbf{3}$ are shown. Note that the aromatic region has been enlarged in spectra b-h. Legend: $\left(^{*}\right)$ residual solvent peaks; $(* *)$ cocrystallized acetone; (***) water.

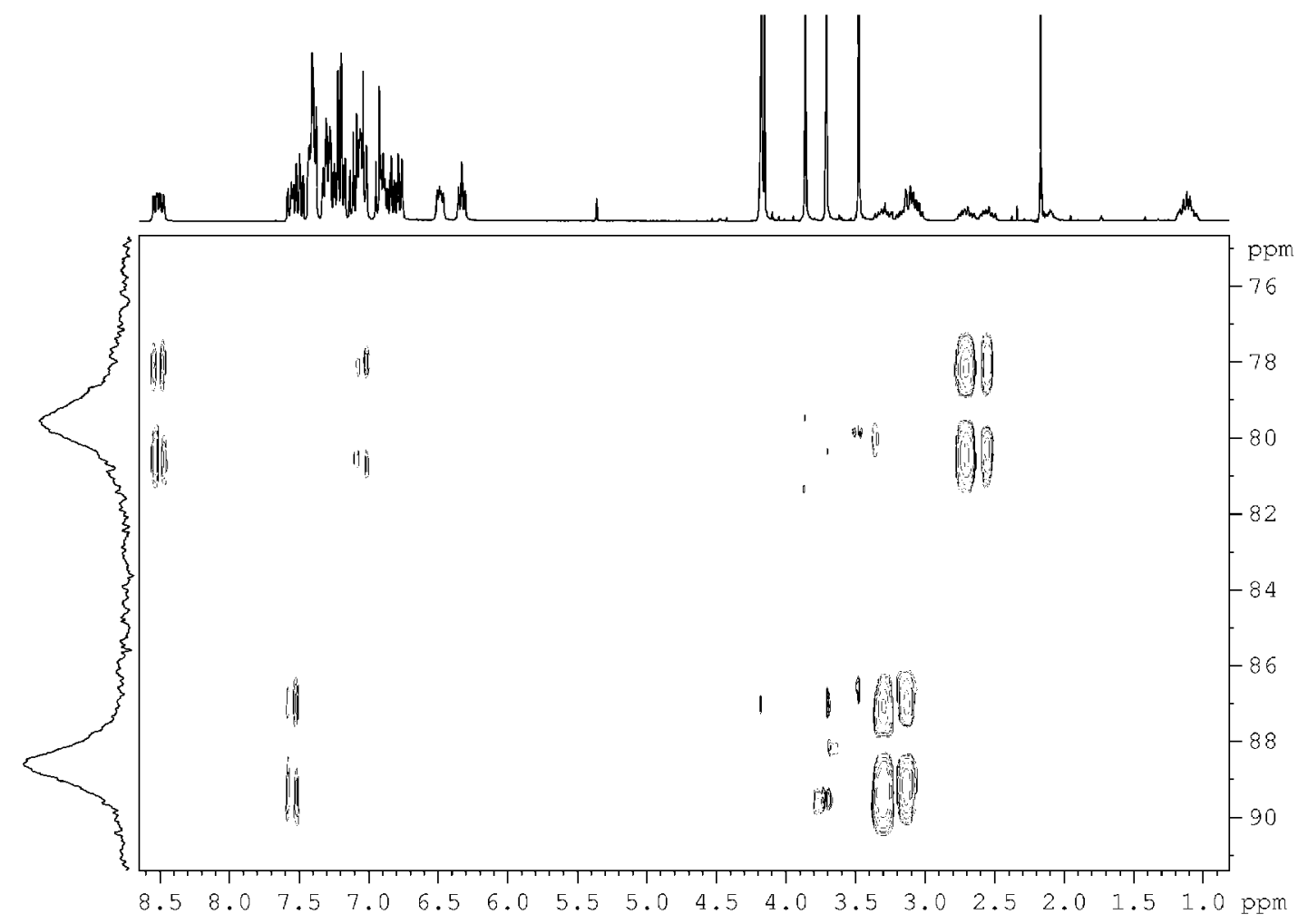

Figure 5. Room-temperature ${ }^{1} \mathrm{H}-31 \mathrm{P}$ COSY spectrum of 3 in $\mathrm{CD}_{2} \mathrm{Cl}_{2}$.

ppm, which is part of the last set of protons, as ortho proton $\mathrm{H} 36$ of ring $\mathrm{C}$. To discriminate last between rings $A$ and $D, a{ }^{1} H-{ }^{31} \mathrm{P}$ COSY spectrum was recorded, as shown in Figure 5 . Whereas proton $\mathrm{H} 36$ (8.5 ppm) couples with the phosphorus atom at $80 \mathrm{ppm}$ (which must be P5), the ortho proton at $7.5 \mathrm{ppm}$ couples with the other phosphorus atom (P2) and must therefore belong to ring $\mathrm{A}(\mathrm{H} 16)$. The coupling of $\mathrm{H} 46$ with $\mathrm{P} 5$ is observed, while the coupling of ring $B$ is too weak to be observed. Note that a strong ${ }^{3} \mathrm{H}$ H coupling of the bridge protons with both phosphorus atoms is found, whereas the ${ }^{2} \mathrm{~J}$ нP coupling is not visible. ${ }^{33}$

Next, the bridge protons can be assigned. ${ }^{32}$ The two axial protons will not exhibit a mutual NOE cross peak, which is true for the upfield-shifted proton and the proton resonating at $3.1 \mathrm{ppm}$. The equatorial proton $\mathrm{H} 3_{\text {eq }}$ interacts with ring $\mathrm{B}$. The signal at $1.1 \mathrm{ppm}$ is not

(33) Phosphorus-31 NMR: Principles and Applications; Gorenstein, D. G., Ed.; Academic Press: Orlando, FL, 1984; p 37. 
attached to the same carbon as $\mathrm{H}_{\text {eq }}$ and thus can be attributed to $\mathrm{H} 4$ ax.

The downfield shift of $\mathrm{H} 36$ can be explained by its proximity to the ruthenium center, which was also observed in the solid-state structure (vide supra). Complex $\mathbf{2}$ shows a similar chemical shift for two protons, illustrating both the general occurrence of this proximity in ruthenium complexes with o-methoxyphenyl phosphine ligands and the symmetry of $\mathbf{2}$. That the interaction between $\mathrm{H} 36$ and the ruthenium center is maintained in solution is most likely due to the high barrier toward rotation around the $\mathrm{P} 5-\mathrm{C} 31$ bond caused by steric repulsion with both the $\mathrm{Cp}$ ring and ring $\mathrm{D}$. In fact, the methoxy group of ring $C$ is the only one lacking a NOE cross peak with the Cp group, which confirms the absence of rotation of ring $C$ on the NMR time scale. In complexes of nickel with o-MeO-dppe, a similar downfield chemical shift caused by interaction of an ortho proton with the metal center is observed. ${ }^{19}$

The intriguing upfield chemical shift of $\mathrm{H}_{4}$ ax may be explained as fol lows. The bridge protons in $\mathbf{2}$ all appear in the range $2.5-3 \mathrm{ppm}$ and show a broadening that is caused by a dynamic process, inverting axial and equatorial positions ("ring flip"). The possibility of a ring flip in $\mathbf{3}$ is lost due to the additional coordination of the phenolate group. The fixation of the ethylene bridge brings proton $\mathrm{H}_{\mathrm{ax}}$ in close vicinity to the $\pi$-cloud of ring C. The resulting upfield chemical shift is characteristic for this $\mathrm{CH} / \pi$ interaction. ${ }^{27}$ The ${ }^{1} \mathrm{H}$ NMR spectrum of $\mathbf{2}$ does not indicate the existence of $\mathrm{CH} / \pi$ interaction in this complex, as this interaction al one does not provide the necessary energy to fixate the bridge in this position. The solid-state structure as shown in Figure 1 supports the existence of a $\mathrm{CH} / \pi$-interaction in $\mathbf{3}$ with the short distances of $\mathrm{H} 4_{\mathrm{ax}}$ to $\mathrm{C} 31$ and $\mathrm{C} 32 .{ }^{27}$

Dynamic Behavior of 3. Interestingly, the two signals in the room-temperature ${ }^{31} \mathrm{P}$ NMR spectrum are broad singlets instead of the anticipated doublets. As the two chelate rings of $\mathbf{3}$ do not flip (vide supra), complex $\mathbf{3}$ must be engaged in another dynamic process, and this has been investigated using both ${ }^{31} \mathrm{P}$ and ${ }^{1} \mathrm{H}$ temperature-dependent NMR spectroscopy. Figure 3 shows the ${ }^{31 P}$ NMR spectra in the range from -100 to $+25^{\circ} \mathrm{C}$. U pon cooling, the broad singlet at $80.1 \mathrm{ppm}$ first broadens further and shifts to lower field. Below the coal escence temperature two new doublets appear in a 7:1 ratio with a chemical shift difference $(\Delta v)$ of approximately $10 \mathrm{ppm}$. The other signal at $89.1 \mathrm{ppm}$, originating from the other phosphorus atom, remains essentially at the same chemical shift over the whole temperature range. Yet, also this singlet splits into two doublets with a $\Delta v$ value of about $1 \mathrm{ppm}$. Thus, both room-temperature signals become two doublets that are integrated in a 7:1 ratio, indicating the existence of two different species at low temperature in which both phosphorus atoms remain bonded to the ruthenium center. The position of the higher field peak in the roomtemperature spectrum ( $80.1 \mathrm{ppm}$, Figure $3 \mathrm{a}$ ) is not the weighted average of the positions of the two peaks in the $-100{ }^{\circ} \mathrm{C}$ spectrum (Figure $3 \mathrm{~h}$ ). This may be explained by the existence of a temperature-dependent equilibrium between two species (vide infra).

The room-temperature ${ }^{1} \mathrm{H}$ NMR spectrum does not show any broadened signals (Figure 4a), but dynamic behavior is observed at lower temperatures (F igure 4bh). Basically, the findings of ${ }^{31} \mathrm{P} N \mathrm{NM}$ are corroborated by ${ }^{1} \mathrm{H} N M R$, where al so two complexes are observed at $-100{ }^{\circ} \mathrm{C}$ in a $7: 1$ ratio. In general, the coalescence is less distinct, but onemethoxy singl et seems to shift and to split into two singlets. The signals of some of the aromatic protons split into two signals as well.

Thus, at $-100{ }^{\circ} \mathrm{C}$ two complexes exist in a 7:1 ratio in which both phosphorus atoms remain bonded to the ruthenium center. The observed chemical shifts exclude coordination of methoxy groups with concomitant dissociation of phosphorus that was observed for other complexes. ${ }^{18}$ The free ligand o-MeO-dppe has a ${ }^{31} \mathrm{P}$ chemical shift of $-31.7 \mathrm{ppm},{ }^{19}$ and the average signal $\langle\mathrm{P}($ bonded) $-\mathrm{P}$ (free) $\rangle$ that would arise if dissociation takes place would ther efore be expected at much higher field than observed. A monomer-dimer equilibrium can be ruled out, since a $6 \times$ diluted solution shows the same 7:1 ratio of both the ${ }^{31} \mathrm{P}$ and ${ }^{1} \mathrm{H}$ resonances. The most likely explanation is the existence of two rotamers: i.e., the rotation of one phenyl ring around the $\mathrm{P}-\mathrm{C}$ bond is relatively slow, and the ring freezes out in two positions at low temperature. The equilibrium between both conformations apparently shifts with temperature, as deduced from the ${ }^{31} \mathrm{P}$ chemical shifts at various temperatures (Figure 3, vide supra). It seems that $\mathbf{3}$ is frozen out in the most stable conformation.

The most likely candidate for restricted rotation is ring D. Ring B obviously cannot rotate. Ring $C$ is also not rotating, as evidenced by the absence of a NOE cross peak of the corresponding methoxy group with the $\mathrm{Cp}$ ring and the downfield chemical shift of H36 that is retained over the complete temperature range. $\mathrm{The}^{1} \mathrm{H}-$ ${ }^{31} \mathrm{P}$ COSY spectrum (Figure 5) reveals that P5, which shows the largest temperature effect, couples with rings $\mathrm{C}$ and $\mathrm{D}$. This is consistent with the variable-temperature ${ }^{1} \mathrm{H}$ NMR spectra (Figure 4), in which the methoxy group of ring $D$ at $3.61 \mathrm{ppm}$ shows the most pronounced temperature effect. The temperature-dependent NMR data allow calculation of the $\Delta \mathrm{G}^{\ddagger}$ value of the rotati on. ${ }^{34,35} \mathrm{~F}$ rom the coalescence temperatures of the ${ }^{31} \mathrm{P}$ signals, the ${ }^{1} \mathrm{H} \mathrm{MeO}$ and aromatic $\mathrm{H} 36$ protons, three estimates average to $\Delta \mathrm{G}^{\ddagger}=41.6 \mathrm{~kJ} \mathrm{~mol}^{-1}$. The ratio between the two rotamers was established at 7:1 by integration, which implies a difference in $\Delta \mathrm{G}^{\circ}$ of $4.8 \mathrm{~kJ}$ $\mathrm{mol}^{-1}$

Catalytic Activity. Complex $\mathbf{1}$ has been reported to sel ectively catalyze the isomerization of allylic alcohols in the presence of unfunctionalized alkene moieties. ${ }^{36,37}$ The isomerization reaction can be significantly accelerated by incorporating more labile ligands into the catalyst precursor. Thus, $\left[\mathrm{RuCp}(\mathrm{MeCN})_{2}\left(\mathrm{PPh}_{3}\right)\right]^{+}$reaches rates (TOFs) of up to $30000 \mathrm{~h}^{-1} .38$ Most effective is the complete removal of chloride by addition of a silver(I) salt with noncoordinating anions. ${ }^{6}$ In this case, TOFs of over $200000 \mathrm{~h}^{-1}$ have been attained with 3-buten-

(34) $\Delta \mathrm{G}^{\ddagger}$ was calculated by using the equation $\Delta \mathrm{G}^{\ddagger}=19.14 \mathrm{~T}_{\mathrm{C}}(9.97$ $+\log \left(T_{d} d \Delta v\right) J \mathrm{~mol}^{-1}$, where $T_{c}$ is the coal escence temperature $(\mathrm{K})$ and $\Delta v$ the shift difference $(\mathrm{Hz})$ of the two exchanging sites in the limiting low-temperature spectrum.

(35) Günther, H. NMR Spectroscopy. An Introduction; Wiley: New York, 1973; p 243.

(36) Trost, B. M.; Kulawiec, R. J J J Am. Chem. Soc. 1993, 115, 2027.

(37) Trost, B. M.; Kulawiec, R. J. Tetrahedron Lett. 1991, 32, 3039.

(38) Slugovc, C.; Ruba, E.,; Schmid, R.; Kirchner, K. Organometallics 1999, 18, 4230. 
Scheme 2. Proposed Mechanism for the Isomerization of Allylic Alcohols, Catalyzed by $3^{a}$

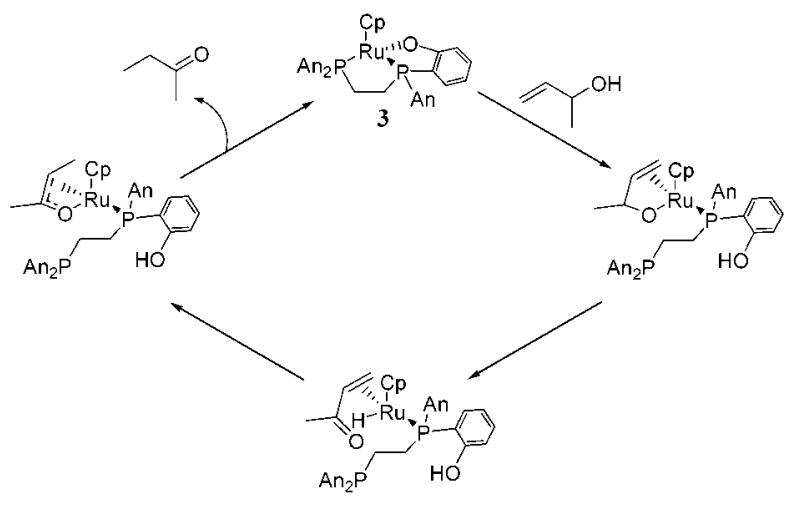

${ }^{a} \mathrm{An}=\mathrm{o}-\mathrm{MeO}-\mathrm{Ph}$.

2-ol as substrate. Replacement of the monodentate phosphine ligands by didentate phosphines results in slightly lower rates, but they are still considerably higher than reported for most other catalysts. ${ }^{2}$ In that light, it is interesting to attempt the use of $\mathbf{3}$ as a catalyst precursor in the isomerization of allylic alcohols, as the absence of chloride circumvents the need for silver(I) salts. In addition, $\mathbf{3}$ is stable in solution for prolonged periods, whereas cationic ruthenium-cyclopentadienyl complexes with noncoordinating anions are highly sensitive to air oxidation. I ndeed, $\mathbf{3}$ catalyzes the isomerization of 3-buten-2-ol to MEK, al beit at low rates: an initial turnover frequency of $35 \mathrm{~h}^{-1}$ is observed with a cumulative turnover number of 100 after $5 \mathrm{~h}$. Internal double bonds, such as in 2-buten-1-ol, are not isomerized.

A possible mechanism for the isomerization has been proposed by Trost and co-workers ${ }^{36}$ and subsequently slightly refined and adapted to accommodate the didentate ligands. ${ }^{6}$ To be catalytically active, $\mathbf{3}$ has to be able to have at least two sites available, which is not easily attained with the strongly coordinating tridentate ligand present. A tentative isomerization route for 3-buten-2ol is shown in Scheme 2. Protonation of the phenolate and subsequent coordination of substrate alkoxide is followed by $\beta$-hydrogen abstraction. The resulting ruthenium-enone hydride rearranges to a ruthenium oxaallyl species. Finally, protonation of the oxaallyl and tautomerization yields MEK and regenerates 3.

\section{Conclusion}

3 can be prepared quantitatively in situ from [Ru$\mathrm{ClCp}\left(\mathrm{PPh}_{3}\right)_{2}$ ] and o-M eO-dppe at $135^{\circ} \mathrm{C}$ under sponta- neous $\mathrm{MeCl}$ abstraction. This results in a unique tridentate $P, P, O$ ligand. The solid-state structure of $\mathbf{3}$ features two molecules in the unit cell with opposite stereochemistry at the ruthenium center and one phosphorus atom $\left(\mathrm{Ru}_{S} \mathrm{P}_{S}\right.$ and $\left.\mathrm{Ru}_{\mathrm{R}} \mathrm{P}_{\mathrm{R}}\right)$. One aromatic ortho hydrogen is in close contact $(3.1315 \AA$ ) with the ruthenium center. Furthermore, one axial bridge proton shows a $\mathrm{CH} / \pi$ interaction with a nearby aromatic ring, as evidenced by the short distances of 2.839 and 3.115 $\AA$ to two ring carbons.

The solution structure of complex $\mathbf{3}$ can be described as a ruthenium center, to which are coordinated an $\eta^{5}$ $\mathrm{Cp}$ group and the ligand tappe in a tridentate fashion through both phosphorus atoms and the phenolate oxygen moi ety. Thus, 3 is locked in solution in the same conformation it has in the solid state by the phenolate group on one hand and the steric repulsion of the methoxy groups on the other hand. This conformational locking results in two peculiar chemical shifts of protons that are forced into their respective positions; the rare $\mathrm{CH} / \pi$ interaction that was observed in the solid-state structure is retained in solution, as is the proximity of $\mathrm{H} 36$ to the ruthenium center. Two of the four aromatic rings in the tappe ligand do not rotate. Of the two other rings, ring $A$ most likely shows unhindered rotation, even down to $-100{ }^{\circ} \mathrm{C}$. Finally, ring $\mathrm{D}$ exhibits a restricted rotation $\left(\Delta \mathrm{G}^{\ddagger}=41.6 \mathrm{~kJ} \mathrm{~mol}{ }^{-1}\right)$, which gives rise to line broadening in the room-temperature ${ }^{31} \mathrm{P}$ NMR spectrum and low-temperature ${ }^{1} \mathrm{H}$ NMR spectra.

The catalytic activity of $\mathbf{3}$ (TOF $=35 \mathrm{~h}^{-1}$ ) is low compared to complexes with didentate or monodentate phosphines. This may be explained by the difficulty of creating two vacant sites, required for isomerization activity, which can be achieved by protonation of the phenolate group and subsequent opening up of both chelate rings.

Acknowledgment. This research was supported by the Technology Foundation STW, the applied science division of NWO, and the technology program of the Ministry of Economic Affairs. This work was supported in part (A.L.S.) by the Council for Chemical Sciences of The Netherlands Organization for Scientific Research (CW-NWO). Dr. J . G. de Vries (DSM in The Netherlands) and Mr. W. G. Reman (SRTCA in The Netherlands) are thanked for stimulating discussions.

Supporting Information Available: Tables giving crystal data and structure refinement details for $\mathbf{3}$ and figures giving selected NMR spectra. This material is available free of charge via the Internet at http://pubs.acs.org.

OM020218P 